\title{
Recent hybrid origin of three rare Chinese turtles
}

Bryan L. Stuart ${ }^{1,2, *}$ \& James F. Parham ${ }^{3,4}$

${ }^{1}$ The Field Museum, Department of Zoology, Division of Amphibians \& Reptiles, 1400

South Lake Shore Drive, Chicago, IL 60605-2496 USA (bstuart@fieldmuseum.org);

${ }^{2}$ University of Illinois at Chicago, Department of Biological Sciences, 845 West Taylor,

Chicago, IL 60607-7060 USA; ${ }^{3}$ Evolutionary Genomics Department, Joint Genome

Institute, 2800 Mitchell Drive, Walnut Creek, CA 94598 USA

(parham@socrates.berkeley.edu); ${ }^{4}$ Museum of Paleontology, 1101 Valley Life Sciences

Building, University of California, Berkeley, CA 94720 USA

(*Corresponding author: Phone: +312-665-7722; Fax: +312-665-7932; E-mail:

bstuart@fieldmuseum.org)

Keywords: Geoemydidae, hybridization, conservation, nuclear DNA

Running Title: Hybrid origin of rare Chinese turtles

\begin{abstract}
Three rare geoemydid turtles described from Chinese trade specimens in the early 1990s, Ocadia glyphistoma, O. philippeni, and Sacalia pseudocellata, are suspected to be hybrids because they are known only from their original descriptions and because they have morphologies intermediate between other, better-known species. We cloned the
\end{abstract}


alleles of a bi-parentally inherited nuclear intron from samples of these three species. The two aligned parental alleles of $O$. glyphistoma, O. philippeni, and S. pseudocellata have 5-11.5 times more heterozygous positions than do 13 other geoemydid species. Phylogenetic analysis shows that the two alleles from each turtle are strongly paraphyletic, but correctly match sequences of other species that were hypothesized from morphology to be their parental species. We conclude that these rare turtles represent recent hybrids rather than valid species. Specifically, "O. glyphistoma" is a hybrid of Mauremys sinensis and $M$. cf. annamensis, "O. philippeni” is a hybrid of M. sinensis and Cuora trifasciata, and "S. pseudocellata" is a hybrid of C. trifasciata and S.

quadriocellata. Conservation resources are better directed toward finding and protecting populations of other rare Southeast Asian turtles that do represent distinct evolutionary lineages.

\section{Introduction}

Turtles are heavily exploited in Southeast Asia for food, traditional medicine, and pets (van Dijk et al. 2000), and now more than half of Asian species are listed as endangered or critically endangered in the wild (Stuart and Thorbjarnarson 2003; IUCN 2004). At the same time, these demands have fueled large-scale turtle farming operations in southern China (Shi and Parham 2001; Shi et al. 2004), a development that has greatly increased the potential for hybridization and genetic admixture of turtles found in trade.

During the last two decades, 14 new species of geoemydid turtles were described from China (Parham et al. 2001; Spinks et al. 2004), and these represent a significant 
proportion of China's turtle diversity (Stuart and Thorbjarnarson, 2003). Most of these newly described taxa were based on specimens purchased from a Hong Kong pet dealer named Yuk Wah "Oscar" Shiu (Parham et al. 2001; Dalton 2003). Three of these species, "Mauremys iversoni," "M. pritchardi," and "Cuora serrata," are now known to be hybrids based on morphology, mitochondrial DNA, and nuclear DNA data (Parham et al. 2001; Wink et al. 2001; Stuart and Parham 2004; Spinks et al. 2004). Specimens matching one of these hybrids, "M. iversoni," have been found in Chinese turtle farms where the parental species $M$. mutica and $C$. trifasciata are housed together, and where farm operators acknowledge producing and selling the hybrids (Parham and Shi 2001; Parham et al. 2001). However, a specimen matching another of these hybrids, " $C$. serrata," has been found in the wild (Shi et al. 2005), and so multiple explanations may be required to account for the origin of all hybrid specimens (Parham et al. 2001; Shi et al. 2005). Reproductive isolating mechanisms of geoemydid turtles appear to be relatively weak. Nineteen hybridizations between geoemydid species are now documented, including between members of distantly related lineages (reviewed in Buskirk et al. 2005).

Three additional Chinese species are now suspected to be hybrids because they are known only from their original descriptions (based on specimens obtained from $\mathrm{O}$. Shiu) and because they have morphologies intermediate between other well-known species (Parham and Shi 2001; Parham et al. 2001; Shi and Parham 2001; Dalton 2003; Spinks et al. 2004; Buskirk et al. 2005; Figure 1). Ocadia glyphistoma McCord and Iverson, 1994 was described from ten specimens (one preserved, nine living in the private collection of W. P. McCord) reported to have been purchased by O. Shiu from local 
people in Guangxi Province, China. Ocadia philippeni McCord and Iverson, 1992 was described from nine specimens (two preserved, seven living in the private collection of W. P. McCord) reported to have been purchased by O. Shiu from local people in Hainan Province, China. Sacalia pseudocellata Iverson and McCord, 1992 was described from three specimens (two preserved, one living in the private collection of W. P. McCord) also reported to have been purchased by O. Shiu from local people in Hainan Province, China.

Assessing the taxonomic status of O. glyphistoma, O. philippeni, and $S$. pseudocellata is more than academic. These three species are known from only a very small number of specimens collected 15 or more years ago, are reported to be harvested by local people, and are reported to occur in southern China, an area with very high levels of turtle harvest and trade (Lau and Shi 2000). If these three species represent valid taxa, they are likely to be threatened with extinction. However, if these three species represent recent hybrids, then conservation resources should be directed away from them and toward legitimate Southeast Asian turtle taxa that are threatened in the wild (van Dijk et al. 2000; Parham et al. 2001; Stuart and Thorbjarnarson 2003; Parham et al. 2004). Currently, these three species are listed as data deficient in the 2004 IUCN Red List of Threatened Species, meaning "there is inadequate information to make a direct, or indirect, assessment of its risk of extinction" (IUCN 2004).

A recent survey of mitochondrial DNA variation in geoemydid turtles by Spinks et al. (2004) included blood samples from a specimen of $O$. glyphistoma, O. philippeni, and S. pseudocellata living in the private collection of W. P. McCord. Because mitochondrial DNA is maternally inherited, hybridization would be detected by 
mitochondrial DNA only if the mother belonged to the "wrong" phylogenetic clade (Spinks et al. 2004). The sample of $O$. glyphistoma was found to have mitochondrial DNA closely related to $M$. annamensis, and the authors concluded it was a hybrid having an M. annamensis mother. The father was assumed to be Mauremys (formerly Ocadia; Feldman and Parham 2004; Spinks et al. 2004) sinensis on the basis of the morphological similarity of $O$. glyphistoma with $M$. sinensis. The mitochondrial results from the other two species were ambiguous. The mitochondrial DNA of $O$. philippeni closely matched that of "M. iversoni," a known hybrid of $M$. mutica and Cuora trifasciata, within a clade of Cuora, but was distinct from another sample of $C$. trifasciata. The mitochondrial DNA of $S$. pseudocellata was closely related to $S$. quadriocellata, a well-known species (Spinks et al. 2004).

We test the recent hybrid origin hypothesis for O. glyphistoma, O. philippeni, and S. pseudocellata by cloning a bi-parentally inherited nuclear intron from the same blood samples studied by Spinks et al. (2004). We then reconstruct the phylogenetic position of these parental alleles within relevant geoemydid turtles. A sample of "Cuora serrata," known to be a hybrid between a male $C$. mouhotii and a female $C$. bourreti (Parham et al. 2001; Stuart and Parham 2004), is included as a positive control.

\section{Materials and methods}

Total genomic DNA was extracted from tissues (Table 1) using PureGene Animal Tissue DNA Isolation Protocol (Gentra Systems, Inc.). A fragment of nuclear DNA containing an intron and part of flanking exons 1 and 2 of the RNA fingerprint protein 35 (R35) 
gene was amplified by EPIC PCR (exon-primed-intron-crossing polymerase chain reaction; $94^{\circ} \mathrm{C} 45 \mathrm{~s}, 54^{\circ} \mathrm{C} 30 \mathrm{~s}, 72^{\circ} \mathrm{C} 1 \mathrm{~min}$ ) for 35 cycles using the primers $\mathrm{R} 35 \mathrm{Ex} 1$ and R35Ex2 (Fujita et al. 2004). PCR products of “C. serrata,” O. glyphistoma, O. philippeni, and S. pseudocellata were cloned using a TOPO TA Cloning kit (Invitrogen) to isolate the two parental alleles. Seven cloned colonies of each turtle were re-amplified. PCR products were electrophoresed in a $1 \%$ low melt agarose TALE gel stained with ethidium bromide and visualized under ultraviolet light. The bands containing DNA were excised and agarose was digested from bands using GELase (Epicentre Technologies). PCR products were sequenced in both directions by direct double strand cycle sequencing using Big Dye version 3 chemistry (Perkin Elmer). The amplifying primers and two internal primers, L-R35int (5'-AGCATTACTACATTTTGATGCAATG-3') and HR35int (5'-CCAGCAAAGGACTCACTTGTA-3'), were used in the sequencing reactions. Cycle sequencing products were precipitated with ethanol, $3 \mathrm{M}$ sodium acetate, and $125 \mathrm{mM}$ EDTA, and sequenced with a 3730 DNA Analyzer (ABI). Sequences were edited and aligned using Sequencher v. 4.1 (Genecodes). The two parental alleles of " $C$. serrata," O. glyphistoma, O. philippeni, and S. pseudocellata were aligned to each other to count heterozygous positions, but were maintained as separate sequences in phylogenetic analyses. The total alignment contained 1156 characters.

Phylogenies were reconstructed using the maximum parsimony and maximum likelihood optimality criteria implemented in PAUP* $4.0 \mathrm{~b} 10$ (Swofford 2002). Maximum parsimony analyses were performed with equal weighting of nucleotide substitutions using the branch-and-bound search option. The model of sequence evolution that best described the data was inferred using the Akaike Information Criterion as implemented in 
Modeltest 3.7 (Posada and Crandall 1998). The selected model was HKY + I, with base frequencies $\mathrm{A}=0.2801, \mathrm{C}=0.1816, \mathrm{G}=0.2054$, and $\mathrm{T}=0.3328, \mathrm{ti} / \mathrm{tv}$ ratio $=2.3601$, and proportion of invariable sites $=0.7487$. Maximum likelihood analyses were performed under this model using the heuristic search option, stepwise addition with 500 random addition replicates, and TBR branch swapping. Nodal support was evaluated with 1000 nonparametric bootstrapping pseudoreplications (Felsenstein 1985). The parsimony bootstrapping was limited to 5 min of branch swapping per pseudoreplication. Trees were rooted with the testudinid Testudo hermanni.

The two parental alleles should be closely related if the samples of "C. serrata," O. glyphistoma, O. philippeni, and S. pseudocellata do not have a recent hybrid origin. To test the null hypotheses that these taxa do not have a recent hybrid origin, likelihood trees were reconstructed using the same model of sequence evolution but with the two parental alleles of one taxon constrained to be monophyletic in each tree. The likelihood scores of the four constrained trees were compared against the unconstrained tree using the Shimodaira-Hasegawa (SH) test (Shimodaira and Hasegawa 1999) with RELL optimization implemented in PAUP* 4.0b10. Mann-Whitney U tests were performed using SPSS 13.0.

\section{Results}

The two aligned parental alleles of "C. serrata," O. glyphistoma, O.philippeni, and S. pseudocellata contained 38, 18, 10, and 23 heterozygous positions (including insertiondeletions), respectively, whereas the 22 sequences of the other 13 geoemydid species 
contained 0-2 heterozygous positions. The difference in number of heterozygous positions between these two groups is highly significant $(\mathrm{p}<0.001$, Mann-Whitney $\mathrm{U}$ test), with or without the inclusion of the known hybrid "C. serrata."

Of the 1156 aligned characters, 85 were variable and 37 were parsimonyinformative. Maximum parsimony and maximum likelihood analyses recover the same hypothesis of phylogenetic relationships (Figure 2), except that one of the two equally most parsimonious trees places the clade containing S. quadriocellata and $S$.

pseudocellata Allele B as sister to the genus Cuora. The two parental alleles of " $C$. serrata," O. glyphistoma, O. philippeni, and S. pseudocellata are strongly paraphyletic (Figure 2). "Cuora serrata" has alleles closely related to C. bourreti and C. mouhotii. Ocadia glyphistoma has one allele closely related to $M$. cf. annamensis and one allele identical to M. sinensis. Ocadia philippeni has alleles closely related to C. trifasciata and M. sinensis. Sacalia pseudocellata has alleles closely related to C. trifasciata and S. quadriocellata. SH tests showed the unconstrained tree (- $\ln L$ 2261.79875; Figure 2) had a significantly better likelihood score than any of the trees constrained to have monophyletic parental alleles of "C. serrata" (-ln L 2293.14984, $p=0.005), O$. glyphistoma $(-\ln L 2294.07329, p=0.003)$, O. philippeni $(-\ln L 2299.61171, p=0.008)$, or S. pseudocellata $(-\ln L 2324.40705, p=0.000)$.

\section{Discussion}

Nuclear DNA sequence data strongly support the hypothesis of a recent hybrid origin of O. glyphistoma, O. philippeni, and S. pseudocellata. First, the sequences of these taxa 
have 5-11.5 times more heterozygous positions than do 13 other geoemydid taxa, of which 12 are well-known species. A high number of heterozygous positions are also found in the known hybrid " $C$. serrata." Second, the two parental alleles of $O$. glyphistoma, O. philippeni, and S. pseudocellata are more closely related (or identical) to sequences of other geoemydid species than to each other. The two parental alleles of $O$. glyphistoma, O. philippeni, and S. pseudocellata correctly match sequences of species that were hypothesized to be the parental species based on morphology (Parham et al. 2001; Dalton 2003) and, in the case of O. glyphistoma, on morphology and mitochondrial DNA (Spinks et al. 2004). Likewise, the two parental alleles of the known hybrid ' $C$. serrata' correctly match sequences of its parental species, C. mouhotii and C. bourreti (Parham et al. 2001; Stuart and Parham 2004). Using published mitochondrial DNA data from the same samples (Spinks et al. 2004) to distinguish the maternal species from the paternal species, we conclude that the sample of "O. glyphistoma" is the progeny of a male $M$. sinensis and a female $M$. cf. annamensis, the sample of "O. philippeni" is the progeny of a male $M$. sinensis and a female $C$. trifasciata, and the sample of " $S$. pseudocellata" is the progeny of a male C. trifasciata and a female S. quadriocellata. Ironically, the maternal lineage of "O. glyphistoma," referred to here as $M$. cf. annamensis, is itself a Southeast Asian geoemydid of uncertain taxonomic status in need of study. These turtles are closely related to M. annamensis in mitochondrial DNA, but are readily distinguished from $M$. annamensis in morphology (J. J. Fong, J. F. Parham and B. L. Stuart, unpublished data). Our findings support the observation that most geoemydid hybridizations involve at least one member of the genera Mauremys and Cuora, and that hybridization can occur between these genera and the distantly related 
genus Sacalia (Buskirk et al. 2005). The method proved simple and effective for identifying hybridization, and demonstrates a new utility for the R35 intron in turtles.

The parental species of "O. glyphistoma," "O. philippeni," and "S. pseudocellata" have overlapping geographic ranges (Iverson 1992) and are raised in Chinese turtle farms (Shi and Parham 2001; Shi et al. 2004), and consequently these hybrids may have originated in the wild or in captivity. Some authors have openly questioned the veracity of locality information provided by O. Shiu (Parham and Li 1999; de Bruin and Artner 1999; Dalton 2003; Shi et al. 2005). We treat "O. glyphistoma," "O. philippeni," and "S. pseudocellata" as invalid species, and unless they are discovered to be members of natural hybrid zones, we suggest that their conservation value is limited to serving as substitutes for wild-caught individuals of legitimate taxa in the food, traditional medicine, and pet trade (Parham and Shi 2001; Spinks et al. 2004). Conservation resources are better directed toward finding and protecting populations of other rare Southeast Asian turtle taxa that do represent distinct evolutionary lineages. For example, the box turtles $C$. mccordi, C. picturata, C. yunnanensis, and C. zhoui represent distinct evolutionary lineages described from pet trade and market specimens, but remain unknown in the wild (Parham et al. 2004; Stuart and Parham 2004).

\section{Acknowledgements}

Philip Q. Spinks and H. Bradley Shaffer of the University of California, Davis made this study possible by loaning blood samples of $O$. glyphistoma, $O$. philippeni, and $S$. pseudocellata. Robert W. Murphy of the Royal Ontario Museum, and Uwe Fritz of the 
Staatliches Museum für Tierkunde, Dresden loaned tissue samples of additional taxa. Harold Voris, Alan Resetar, and Jamie Ladonski facilitated the use of tissues deposited at the Field Museum. Sequencing was conducted in the The Field Museum's Pritzker Laboratory for Molecular Systematics and Evolution operated with support from the Pritzker Foundation. Erin Sackett assisted with cloning. Richard Banks and Roy W. McDiarmid granted permission to reproduce figures from the Proceedings of the Biological Society of Washington. This research is LBNL-59607 and was performed under the auspices of the U. S. Department of Energy's Office of Biological and Environmental Research and by the University of California, Lawrence Berkeley National Laboratory under Contract No. DE-AC02-05CH11231. This research is also University of California Museum of Paleontology Contribution \# 1920. This research was supported by a National Science Foundation postdoctoral fellowship to JFP. Philip Q. Spinks and two anonymous reviewers critiqued the manuscript.

\section{References}

Buskirk JR, Parham JF, Feldman CR (2005) On the hybridisation between two distantly related Asian turtles (Testudines: Sacalia x Mauremys). Salamandra, 41, 21-26.

Dalton R (2003) Mock turtles. Nature, 423, 219-220.

de Bruin, RWF, Artner HG (1999) On the turtles of Hainan Island, southern China. Chel. Conserv. Biol., 3, 479-486. 
Feldman CR, Parham JF (2004) Molecular systematics of the Old World stripe-necked turtles (Testudines: Mauremys). Asiat. Herpetol. Res., 10, 28-37.

Felsenstein J (1985) Confidence limits on phylogenies: an approach using the bootstrap. Evolution, 39, 783-791.

Fujita MK, Engstrom TN, Starkey DE, Shaffer HB (2004) Turtle phylogeny: insights from a novel nuclear intron. Mol. Phylogenet. Evol., 31, 1031-1040.

IUCN (2004) Red List of threatened species. Available from http://www.redlist.org (downloaded 28 January 2006).

Iverson JB (1992) A Revised Checklist with Distribution Maps of the Turtles of the World. Green Nature Books, Homestead, Florida, USA.

Iverson JB, McCord WP (1992) A new Chinese eyed turtle of the genus Sacalia (Batagurinae: Testudines). Proc. Biol. Soc. Wash., 105, 426-432.

Lau M, Shi H (2000) Conservation and trade of terrestrial and freshwater turtles and tortoises in the People's Republic of China. In: Asian Turtle Trade: Proceedings of a Workshop on Conservation and Trade of Freshwater Turtles and Tortoises in Asia (eds. van Dijk PP, Stuart BL, Rhodin AGJ), pp. 30-38. Chelonian Research 
Monographs No. 2. Chelonian Research Foundation, Lunenburg, Massachusetts, USA.

McCord WP, Iverson JB (1992) A new species of Ocadia (Testudines: Bataguridae) from Hainan Island, China. Proc. Biol. Soc. Wash., 105, 13-18.

McCord WP, Iverson JB (1994) A new species of Ocadia (Testudines: Bataguridae) from southwestern China. Proc. Biol. Soc. Wash., 107, 52-59.

Parham JF, Li D (1999) A new locality for Cuora pani Song 1984 with comments on its known range. Asiat. Herpetol. Res., 8, 111-113.

Parham JF, Shi H (2001) The discovery of Mauremys iversoni-like turtles at a turtle farm in Hainan Province, China: the counterfeit golden coin. Asiat. Herpetol. Res., 9, $71-76$.

Parham JF, Simison WB, Kozak KH, Feldman CR, Shi H (2001) New Chinese turtles: endangered or invalid? A reassessment of two species using mitochondrial DNA, allozyme electrophoresis and known locality specimens. Anim. Conserv., 4, 357367.

Parham JF, Stuart BL, Bour R, Fritz U (2004) Evolutionary distinctiveness of the extinct Yunnan box turtle (Cuora yunnanensis) revealed by DNA from an old museum specimen. Proc. R. Soc. Lond. B (Biol. Lett. Suppl.), 271, S391-S394. 
Posada D, Crandall KA (1998) Modeltest: testing the model of DNA substitution. Bioinformatics, 14, 817-818.

Shi H, Parham JF (2001) Preliminary observations of a large turtle farm in Hainan Province, People's Republic of China. Turt. and Tort. Newsl., 3, 4-6.

Shi H, Fan Z, Yin F., Yuan Z (2004) New data on the trade and captive breeding of turtles in Guangxi Province, South China. Asiat. Herpetol. Res., 10, 126-128.

Shi H, Parham JF, Simison WB, Wang J, Gong S, Fu B (2005) A report on the hybridization between two species of threatened Asian box turtles (Testudines: Cuora) in the wild on Hainan Island (China) with comments on the origin of 'serrata'-like turtles. Amphibia-Reptilia, 26, 377-381.

Shimodaira H, Hasegawa M (1999) Multiple comparisons of log-likelihoods with applications to phylogenetic inference. Mol. Biol. Evol., 16, 1114-1116.

Spinks PQ, Shaffer HB, Iverson JB, McCord WP (2004) Phylogenetic hypotheses for the turtle family Geoemydidae. Mol. Phylogenet. Evol., 32, 164-182.

Stuart BL, Parham JF (2004) Molecular phylogeny of the critically endangered Indochinese box turtle (Cuora galbinifrons). Mol. Phylogenet. Evol., 31, 164-177. 
Stuart BL, Thorbjarnarson J (2003) Biological prioritization of Asian countries for turtle conservation. Chel. Conserv. Biol., 4, 642-647.

Swofford DL (2002) PAUP*: Phylogenetic Analysis Using Parsimony *(and Other Methods), Version 4.0b10. Sinauer Associates, Sunderland, Massachusetts, USA.

van Dijk PP, Stuart BL, Rhodin AGJ, eds. (2000) Asian Turtle Trade: Proceedings of a Workshop on Conservation and Trade of Freshwater Turtles and Tortoises in Asia. Chelonian Research Monographs No. 2. Chelonian Research Foundation, Lunenburg, Massachusetts, USA.

Wink M, Guicking D, Fritz U (2001) Molecular evidence for hybrid origin of Mauremys iversoni Pritchard et McCord, 1991, and Mauremys pritchardi McCord, 1997 (Reptilia: Testudines: Bataguridae). Zool. Abh. Mus. Tierkd. Dresden, 51, 41-49. 
Figure 1. Images of living Ocadia glyphistoma, O. philippeni, and Sacalia pseudocellata modified from their original descriptions with permission of the Proceedings of the Biological Society of Washington. Each of these taxa possesses a combination of characters found in other geoemydid species. A) O. glyphistoma has the numerous small neck stripes (right arrow) of Mauremys (formerly Ocadia) sinensis, but also has the wide temporal stripes (left arrow) of the M. annamensis-M. mutica species complex. B) $O$. philippeni has the numerous small neck stripes (right arrow) of $M$. (formerly Ocadia) sinensis, but also has the yellow head, brown postorbital blotch (left arrow), and red plastron of Cuora trifasciata. C) S. pseudocellata has the diagnostic dorsal "eye spots" on its head (center arrow) and few, thick neck stripes (right arrow) of S. quadriocellata, but also has the yellow head, brown postorbital blotch (left arrow), and red plastron of $C$. trifasciata.

Figure 2. The single maximum likelihood tree $(-\ln L$ 2261.79875) based on 1156 aligned characters of the nuclear R35 gene using the HKY + I model of sequence evolution, base frequencies $\mathrm{A}=0.2801, \mathrm{C}=0.1816, \mathrm{G}=0.2054$, and $\mathrm{T}=0.3328$, ti/tv ratio $=2.3601$, and proportion of invariable sites $=0.7487$. The same topology was recovered in one of two equally most parsimonious trees $(\mathrm{L}=97)$, but the alternative most parsimonious tree places the clade containing Sacalia quadriocellata and S. pseudocellata Allele B as the sister clade to the genus Cuora. Four hybrid taxa (bold-face) appear twice in the tree because their two parental alleles were isolated by cloning. Numbers above and below nodes are non-parametric likelihood and parsimony bootstrap values $>50$, respectively. Numbers in parentheses refer to ID number in Table 1. 
Table 1. Samples used in this study and the GenBank accession numbers of their R35 sequences. ID refers to the terminal taxon in figure 1. Abbreviations used are FMNH = The Field Museum, Chicago; HBS = tissue collection of H. Bradley Shaffer at University of California, Davis; MTD T = Staatliches Museum für Tierkunde, Dresden; MVZ= Museum of Vertebrate Zoology, Berkeley; ROM = Royal Ontario Museum, Toronto.

\begin{tabular}{cllll}
\hline \hline ID & \multicolumn{1}{c}{ Species } & Sample & Provenance & GenBank \\
\hline 1 & Cuora amboinensis & FMNH 262239 & Pet trade & DQ386653 \\
2 & Cuora amboinensis & FMNH 255262 & Champasak Prov., Laos & DQ386654 \\
3 & Cuora bourreti & FMNH 261578 & Pet trade & DQ386657 \\
4 & Cuora bourreti & FMNH 261579 & Pet trade & DQ386658 \\
5 & Cuora flavomarginata & MVZ 230464 & Zhejiang Prov., China & DQ386659 \\
6 & Cuora galbinifrons & FMNH 261580 & Pet trade & DQ386660 \\
7 & Cuora galbinifrons & FMNH 256544 & Khammouan Prov., Laos & DQ386661 \\
8 & Cuora mouhotii & MVZ 230482 & Hainan Prov., China & DQ386667 \\
9 & Cuora picturata & FMNH 261575 & Pet trade & DQ386671 \\
10 & Cuora picturata & FMNH 261576 & Pet trade & DQ386672 \\
11 & Cuora trifasciata & MVZ 230636 & Pet trade & DQ386679 \\
12 & Cuora trifasciata & MVZ 230467 & Pet trade & DQ386680 \\
13 & Cuora trifasciata & MTD T 1082 & Pet trade & DQ386681 \\
14 & Mauremys annamensis & MVZ 230462 & Market in Hainan Prov., China & DQ386655 \\
15 & Mauremys annamensis & FMNH 262238 & Pet trade & DQ386656 \\
16 & Mauremys cf. annamensis & MVZ 230476 & Market in Hainan Prov., China & DQ386664
\end{tabular}


17 Mauremys cf. annamensis

18 Mauremys cf. annamensis

19 Mauremys mutica

20 Mauremys sinensis

21 Sacalia quadriocellata

22 Siebenrockiella crassicollis

23 Testudo hermanni

24 "Cuora serrata"

25 "Ocadia glyphistoma"

26 "Ocadia philippeni"

27 "Sacalia pseudocellata"
MVZ 230477

ROM 25614

MVZ 230487

Zhejiang Prov., China

MVZ 230479 Hainan Prov., China

FMNH 256542 Khammouan Prov., Laos

FMNH 259055 Koh Kong Prov., Cambodia

MVZ 244866 Edirne Prov., Turkey

MVZ 230628 Pet trade

HBS 38414 Pet dealer in Hong Kong, China

HBS 38400

HBS 38432
Pet dealer in Hong Kong, China

Pet dealer in Hong Kong, China
DQ386665

DQ386668

DQ386666

DQ386678

DQ386675

AY954913

DQ386652

DQ386676-77

DQ386662-63

DQ386669-70

DQ386673-74 